University of New Hampshire

University of New Hampshire Scholars' Repository

$1-1-2005$

\title{
Medical, Racist, and Colonial Constructions of Power in Anne Fadiman's The Spirit Catches You and You Fall Down
}

\author{
Monica E. Chiu \\ University of New Hampshire, Durham, monica.chiu@unh.edu
}

Follow this and additional works at: https://scholars.unh.edu/eng_facpub

\section{Comments}

This is an article published in Hmong Studies Journal in 2005, available online: http://hmongstudies.com/

MonicaChiuHSJ5.pdf

\section{Recommended Citation}

Chiu, M.E. "Medical, Racist, and Colonial Constructions of Power in Anne Fadiman's The Spirit Catches You and You Fall Down" in Hmong Studies Journal 5 (2004-2005): http://www.hmongstudies.org/ HmongStudiesJournal.html. Reprinted in Asian American Studies Now: A Critical Reader, Eds. Jean Wu and Thomas Chen. Rutgers University Press, 2010. 370-92.

This Article is brought to you for free and open access by the College of Liberal Arts (COLA) at University of New Hampshire Scholars' Repository. It has been accepted for inclusion in English Scholarship by an authorized administrator of University of New Hampshire Scholars' Repository. For more information, please contact Scholarly.Communication@unh.edu. 
Medical, Racist, and Colonial Constructions of Power: Creating the Asian American Patient and the Cultural Citizen in Anne Fadiman's The Spirit Catches You and You Fall Down by Monica Chiu, Ph.D. Hmong Studies Journal, 2004-05, 5: 1-36.

\title{
Medical, Racist, and Colonial Constructions of Power: Creating the Asian American Patient and the Cultural Citizen in Anne Fadiman's The Spirit Catches You and You Fall Down
}

\author{
By \\ Monica Chiu, PhD \\ University of New Hampshire
}

\author{
Hmong Studies Journal \\ 2004-05, Volume 5, 36 Pages
}

\begin{abstract}
This essay looks at the values attributed or denied to "culture" (medical culture, history, Southeast Asian refugees, Asian American cultural citizenship) in the care surrounding a Hmong child diagnosed with spirit loss, according to Hmong interpretation, or epilepsy, as defined by Western medicine. In my reading of Anne Fadiman's The Spirit Catches You and You Fall Down: A Hmong Child, Her American Doctors, and the Collision of Two Cultures, medical, colonial, and authorial knowledge often converge in devastating ways, linking the seemingly disparate discourses of war, refugee medicine, and the model minority through colonial representations. I also look at the book's lacuna in its investigation of cultural collisions, finding that its approaches to reporting the medical-cultural conflict from a seemingly neutral position-one balancing the reported views of the epileptic child's parents and the views of her medical practitioners-often reinscribe the Hmong subjects into the very colonial parameters from which the book attempts to extract them.
\end{abstract}

\section{Introduction}

This essay is about medical, racist, and colonial constructions of power. It incorporates the following seemingly disparate, but what I will prove to be inextricably connected, discourses: those surrounding the Vietnam War and its subsequent stateside refugee management; current medical care for Southeast Asian patients; and so-called authorial (medical, textual, cultural) constructions of Hmong representation. My critique is based on a reading of literary journalist Anne Fadiman's The Spirit Catches You and You Fall Down: A Hmong Child, Her American Doctors, and the Collision of Two Cultures, ${ }^{1}$ her re-presentation of the actual case of epileptic Hmong American child Lia Lee. Her book raises thorny questions concerning why Lia's "proper" care remains a contentious debate between medical knowledge and Hmong cultural 
practice; how the historical construction of Asian American identity contributes to present and continued Hmong mythologization and feminization and to the Lee's identity as deviant parents; and how Fadiman's often ethnographic, and not always critical, text often contributes to reinscribing her subjects into the very colonial parameters from which she attempts to extract them. My work offers new readings of the book's stated "cultural collisions" in which crosscultural healing is both accomplished and simultaneously denied via practices that Fadiman interrogates and employs.

Briefly, Lia Lee was born in July of 1982, in Merced County, California, to firstgeneration Hmong ${ }^{2}$ refugees Fuoa Lee (her mother) and Nao Kao Lee (her father) as their fourteenth child. Delivered naturally and in good health, she suffered from her first epileptic seizure at three months of age. While the physicians conclude that Lia has suffered from an "electromagnetic storm inside her head," the more eloquent, iatric articulation of an epileptic seizure, they are unaware that the Lees have attributed Lia's symptoms to qaug dab peg, or "the spirit catches you and you fall down." Her family blames her condition on the departure of one of Lia's many spirits - the one responsible for health and happiness-which occurred at the moment her elder sister Yer accidentally slammed the door with such ferocity that she frightened a $d a b$, a spirit, away $(10,20)$. The Lees intend to retrieve the lost $d a b$ through a shaman. The Hmong view those experiencing qaug $d a b$ peg as shamanistic, their seizures mimicking the trance-like states of shamans in the throes of contacting other-world spirits. Hmong medical and spiritual practices are steeped in animism — wherein spirits are ascribed to beings and objects and can be frightened away, causing disease and death-and shamans represent a necessary and positive link between the body and the lost spirit, between the world of the living and the dead. They are the designated arbiters between the corporeal and the spirit world, recalling lost spirits and relaying augurs of ill or good fortune through trance and animal sacrifice. ${ }^{3}$ 
At Merced County Medical Center (MCMC), however, such cultural explanations carry little weight in effecting a cure, even though the hospital had treated numerous Hmong patients since the late 1970s who made so-called unusual medical requests. Throughout Lia's subsequent, numerous, and severe seizures, MCMC legitimizes its own narrative, here the brain's "electromagnetic storm" and the appropriate use of drugs to quell them, despite frequent consternation exhibited by the Lees. Yet the family continues to transport her to the emergency room, placing some faith in Western biomedicine. Much to MCMC's and the Lee's anguish, Lia is eventually pronounced brain dead at five years of age but continues to live a vegetative existence disconnected from any life support system. That both MCMC and the Lees hoped for another outcome is the sole narrative uniting the two fraught parties throughout the ordeal. I therefore probe the limits of medical, colonial, and authorial knowledge and their attendant (often racist) power within this complicated case; my work investigates the value strategically attributed or denied to "culture" (whether medical culture or history) in order to refine the interconnecting parameters within and to respect the intermittent gaps between Lia's illness and health as they are inextricably bound up in a constant negotiation of Asian American cultural citizenship.

My reading of Spirit involves an assessment, mediated by Fadiman, of what counts as knowledge for MCMC, for the nation, for the Lees, and for Fadiman herself, and how such competing knowledge constructs the involved actors and the medical establishment; how such knowledge is shaped by the politics of U.S. colonialism vis-à-vis Southeast Asian refugees and Asian American identity construction, broadly. I map Fadiman's motive to illuminate the Lee's healing beliefs against those of MCMC. Fadiman intends to unpack-yet often inadvertently problematizes - the utility of MCMC's diagnostic praxis in the face of the Lee's mytho-cultural perceptions shaping the life-and-death assumptions of Lia, its central, Asian American patient. Intertwined within this medical case is an historical narrative of the fraught acceptance and rejection of Asian Americans in general, and Hmong acceptance in particular, that exacerbate 
conditions surrounding the treatment of Lia's parents and therefore their growing consternation over Lia's declining condition and their escalating frustration with the MCMC staff. Because the Hmong threaten accepted, routine operations of not only this California County, but of MCMC's health care practices, both Fadiman and I necessarily contextualize the figure of Lia and the crosscultural difficulties surrounding her care. I keep my summaries of necessary historical information - necessary to both understanding Fadiman's argument and to grasping mine - to what I consider a bare minimum. My discussion, unlike Fadiman's, considers how Asian American disruptions to the nation have resulted in Asian Americans' pathologization and internal colonization. That is, Southeast Asian refugees and immigrants (from Laos, Vietnam, Thailand, and Cambodia) are the most recent targets in a national, racist trajectory that has systematically vilified Asian American immigrants as "alien" and "polluting" threats to the health and welfare of the nation despite a seeming vindication as model minorities. ${ }^{4}$ As such, Lia is doubly de-humanized: first by her illness and then by her classification as Asian, which evokes an historical pathologization and feminization of Asian subjects, which I will discuss later. ${ }^{5}$

The frictions animated through Lia about the diagnosis and treatment of her epilepsy occur not only between MCMC's so-called paradigmatic Western (read: masculine) biomedicine ${ }^{6}$ and the Lees' Asian, feminine, mytho-cultural beliefs about the relevance and conception of the body; but the frictions also vex Fadiman's representation of the case in which she criticizes the colonizing practices of MCMC only to replicate them in her portrayal of the Lees.

In this interpolated tale, written by a literary journalist who is neither a medical anthropologist nor an ethnographer, the narrative itself raises puzzling questions about her intent, her authorial method, and her audience. She finds "how hard it was to lay blame at anyone's door"- either with the Lees or Lia's medical staff—-for the child's eventual, vegetative state at five years of age (x). Rather, she blames "crosscultural misunderstanding" for this particularly tragic case deemed "preventable" by Lia's physicians $(262,55)$. Despite such attempts at 
neutrality, Fadiman leans heavily toward sympathizing with the Lees, thus obligating the reader to untangle the various unspoken assumptions and strains that inflect the text and from which one gleans an understanding of Lia, her parents, and her physicians. Within the essay, I offer answers to the following complicated questions: How are Lia's parents being read (or even managed) by Fadiman? Is Fadiman's text a dialogic bridge between medical authority and cultural adherence? If the Lees' words and actions are Fadiman's interpretations of translations-given that her knowledge of the Hmong is circumscribed by her Western ways of thinking and given the Lees' inability to speak English—how do readers responsibly interpret Spirit, especially if the Hmong are known to strategically deliver only "acceptable" cultural information to their Western counterparts? ${ }^{7}$ For whom, then, is the book written? Even if the Lees had spoken for themselves, would we understand their voices as partially constructed fictions accorded to Fadiman's purpose? And most pressing, whom does Spirit serve: did the Lees solicit Fadiman in order to make their story known or did Fadiman pursue this cultural drama? In the third section of the essay, such an analysis of the book's ur-narrative-Fadiman's contextualization through an ethnographic gaze that often renders the Lao Hmong exotic-complicates and contributes to Spirit's complexity and therefore to the urgency of negotiating crosscultural solutions in an increasingly multicultural nation that, unfortunately, practices varying types of subtle but powerful and devastating colonization.

\section{The Effect of Medical and Colonial Narratives on Lia's Case}

Power, both colonial and medical, remains the driving, critical force behind the results of Lia's case, a conclusion that Fadiman herself suggests throughout Spirit and one to which I agree. This section will serve as a necessary overview of Hmong/Southeast Asian history, ${ }^{8}$ the contested acceptance of Asian Americans and their feminization, which redoubles the pathologization of this female, Hmong patient. Lia's case bears out the personal, national, and political cost of 
knowledge: who possesses what constitutes as knowledge, to what and to whose advantage or detriment?

In the particular arena of Hmong medical care in the United States since the late 1970s, crosscultural conflict has proven an impasse in diagnosing and treating the intriguing and perplexing phenomenon of Sudden Unexpected Death Syndrome (SUNDS), in which otherwise healthy Hmong men have been dying from medically unexplained nighttime heart attacks, usually following a nightmare or a bad dream."9 Western medical practitioners are adamant about locating a reasoned, scientific (or proof-based) rationale for these deaths, a medical narrative at odds with a Hmong animist-based explanation in which "death attack" survivors recall the presence of "an incubuslike $d a b$ [spirit] who sits on the victim's chest and presses the breath out of him" (Fadiman 188). Yet in the medical model of patient pathography, in which the patient "presents" her personal story of pathology (or illness narrative) ${ }^{10}$ to the physician, it is then duly translated and legitimized (via specialized medical terminology and nosology) for diagnosis, treatment, and, hopefully, cure. ${ }^{11}$ Unfortunately, Katherine Montgomery Hunter argues, such a process retells and reorders the patient's initial narrative in a manner and context that may very well be conducive to medical epistemology, but one that also effectively erases the patient as subject to render her an object: a case, a study." ${ }^{12}$ In overlooking cultural narratives of illness, such as those Hmong explanations circumscribing SUNDS, patients' and medical practitioners' "logical" explanations compete, often prompting some Hmong patients to forgo medical treatment.

Meanwhile, resistance to biomedicine's socializing/colonizing aspect of Southeast Asian patients has erupted in their manipulation of their own bodies and illnesses in order to "circumvent" the medical system, outlines Aiwha Ong in her study of San Francisco-based Cambodian refugees. By mimicking ills, these refugees continue to receive the social (often financial) support they need; by attending prenatal discussions or keeping doctors' appointments, 
they "maintain official connections that do not threaten their family security" in their host country, but once at home, they continue to "follow their own desires about having babies" or treating their own ills. ${ }^{13}$ In other words, individual cases can alter standard practice as in the creation of Southeast Asian Mental Health. Unfortunately, such attempts have resulted, in part, in further entrenched views of "passive, obedient" and "noncompliant" refugee patients in a health care model whose "constructs are universally applicable, while ignoring the complex micropolitics and consequences of encounters with the health profession," ${ }^{14}$ and thus they clearly bear out Julia Epstein's observation that “[I]f medical "cases” are socially as well as biologically constructed, then case histories participate in producing as well as recording what they observe." 15 Furthermore, in a type of medical and corporeal colonialism, constant revisions of what constitutes acceptable modes of being sick or healthy (a topic pursued later in the essay) demonstrate how patient management can be negotiated to the detriment of the ill and to the advantage of the health care system.

Using such a broad reading of Southeast Asian diseases and the consequences of how they are diagnosed helps to locate the Lee's treatment in the multiethnic, but often racist, matrix of the United States, where internal colonialism constructs these subjects in a manner that often exposes or conceals elements of their history and culture depending on the political outcome desired by the dominant population. Because the Lees, along with Lia's persistent, unmedicatable seizures, threaten MCMC's routine practices and its physicians' medical training, they become symptomatic of a history in which "unassimilable" and "inscrutable" Asian Americans have been posed as perils to national health and welfare, demanding forms of domestication and management. The quintessential strand of such Asian American race abjection is the Yellow Peril, a sociohistoric categorization, emerging in the $1880 \mathrm{~s}$, of Asians as the harbingers of illness and the progenitors of pollution deeply rooted in American rhetoric. From fictions created about so-called diseased and dirty Chinese immigrants ${ }^{16}$ evolved spurious 
medical "facts" and eventually political acts prohibiting the legal and civil actions and internal migrations of not only Chinese but other Asian immigrants as well. ${ }^{17}$ Their "cleaning up" involved not necessarily instructions in bathing habits, but socialization and domestication embodying racist, Western norms. An etiology of Asian American pathology has left a linguistic, semiotic, political, and symbolically bitter trace within American culture. This played out recently in the 1990s when high incidents of tuberculosis and HIV diagnosed in New York's Chinatown re-pathologized the community. ${ }^{18}$ Such narratives rest on biocultural foundations that are derivative of the discursive intersections between fact and fiction and that have plagued social reaction and attendant legislative (colonialist) action against Asian Americans, resulting in the symbolic institutionalization of the Asian American corporeal within this peril/(para)lyzing paradigm even as the attribution of dirty and diseased to the Chinese speaks more to the nation's own preoccupation with moral and medical self-hygiene than to any Other's. ${ }^{19}$

The Lees of Fadiman's book are interpolated by such cultural constructions, becoming part of an historical trajectory illuminating a politically convenient method by which "good" and "bad" Asian Americans have been constructed according to U.S. need. I begin by noting that Lia's pediatricians Neil Ernst and Peggy Philip learn what they can about the Lee's ethnicity by reading "old National Geographic articles about the Hmong," a well-intentioned gesture illuminating a certain dedication to their patient (57). National Geographic, however, represents the epitome of Western anthropological accounting of the "other," a simplified, layperson's introduction to what is often an exoticization — especially photographically—of other cultures and places. ${ }^{20}$ Hardly a self-conscious publication, it is prone to solidifying others through so-called grand narratives of Western anthropology, "othering" "natives" for readers via an "us-and-them" hierarchy, highlighting bodily differences based on color, cultural practice, hygiene, and nutrition. My ideas about what is generalized as Western anthropology are informed by Trinh T. Minh-ha, who categorizes such anthropology as conversations among white men about "others," 
conversations that conveniently overlook the latter's intellectual input about themselves and therefore such Western study offers views reflecting only white values and judgment. ${ }^{21}$ For Neil and Peggy, the publication serves as a catalyst, not a deterrent, to accepted, fixed narratives about the Hmong, emphasizing the devious effects of constructions of knowledge and types of representation of others.

And yet such "fixity" becomes pliable when the stakes for re-interpretation benefit American politics, especially war politics. I consider here the "Secret Wars," a name that describes the silence surrounding Hmong contributions, on behalf of the United States, to the Vietnam "conflict" (as it has unfortunately come to be called). ${ }^{22}$ Many of the West's most successful war efforts in the Laotian jungle were possible only after the CIA's recruitment of Hmong soldiers who had knowledge of and physical agility in their native environment. But their historical value for the West has been fleeting — their representation more fluid than fixed—based exclusively on their contributions toward Western victory over Eastern/Vietcong communist foes, delineating this essay's critique of a narrow adherence to certain narrative strands at the expense of others: the French occupiers enlisted Hmong men who "were 'magnifique' in the jungle" only to abandon them as the Indochinese empire fell; the Americans later trained them on "CIA stockpiled World War II weapons" and depended on their extensive knowledge of the jungle to reach downed U.S. pilots before the Communist forces of the Pathet Lao took them as POWs or killed them. ${ }^{23}$ Thus, while the military is without a doubt one of the most regimented, ordered, and hierarchized of all American political bodies, it warranted the seemingly unorganized and primitive Hmong soldiers to successfully navigate impressive victories amid the equally irrational and dense jungles of Laos, elucidating the West's inability to navigate outside of its ordered ranks, beyond its national boundaries. The deal outlined in what capacity the U.S. would aid the Hmong, in return for their military expertise, in resisting North Vietnamese forces, and the U.S. promised to secure them "a new place" to live and farm if they were defeated by the Pathet Lao. ${ }^{24}$ 
The U.S., unfortunately, did not readily honor either of these promises. Thus, the Lees' skepticism toward biomedicine, bound up in a larger Hmong wariness toward Western solutions to disease, represents their broad-based leeriness toward many American broken promises in which Hmong were deserted and forced to face the murderous Pathet Lao from whom the Americans so quickly fled. Such racist power cannot help but influence refugee distrust. ${ }^{25}$ This conveniently allows the dominant population, viewing the "deviant" behavior of its Southeast Asian constituents, to lay blame on these seemingly problematic citizens. To add injury to insult, some Americans who regard Hmong immigration as increased tax burdens-yet ignorant of their U.S.-backed maneuvers in Vietnam — chafe at hearing that, as Jane Hamilton-Merritt documents, "the Hmong are unique in that they may be the only refugees in the world that do not want to resettle in the U.S.," but would have preferred to return to Laos if that were possible. ${ }^{26}$

These Hmong narratives and their reinscriptions via ignorant American resentment complicate the already convoluted misinformation passing between Americans and Hmong. Because MCMC had witnessed an extensive population of Hmong refugees moving into their county, they were familiar with journalists' often sensationalist representations of the Hmong as "primitive," "low-caste" and "Stone Age" "tribe[s]" (188), and disseminated reports of how community tempers flare over the religious sacrifice of chickens and pigs in Hmong urban living rooms; others, unaware of significant Hmong contribution and devastating personal losses in fighting against Communism with American aid, begrudged their right, as political refugees, to governmental funding through welfare, Medicare, or California's Medi-Cal. For example, the Lees -who became "enemies of the state [of Laos]" for either supporting the U.S. or for "attempt[ing] to remain neutral"- survived two arduous journeys: first to Thai refugee camps, losing three children en route; once in the states, they moved from Portland, Oregon, to Merced, California, enduring racism and ignorance. ${ }^{27}$ Only when the Hmong's culturally incompatible narratives clash with those of their U.S. neighbors - that is, when Hmong war refugees, along 
with those from Vietnam and Cambodia, began arriving to the U.S. in significant numbers-do they become highly visible, highly charged community members. ${ }^{28}$ For MCMC, the necessity to know about the formerly invisible, unknown Hmong is prompted only from emergencies in Lia's care, replicating the manner (via crisis, as in war) by which the Hmong were introduced (made visible as expendable soldiers) to the United States. ${ }^{29}$ While biomedicine makes a concerted, necessary attempt to operate in tandem with other narratives, unfortunately for MCMC, such narratives are bolstered by a type of colonial epistemology. Fadiman references Kleinman's warning that "traditional ethnic stereotypes ... may exert a mischievous influence on care." ${ }^{30}$ In allowing unsubstantiated information to influence MCMC's medical knowledge, and in forgetting how medicine itself contextualizes and attributes value to knowledge, Lia's medical staff overlooks how the particular must be contextualized in the Lees' personal historical and cultural narratives.

That medicine itself adheres to militaristic metaphors exacerbates the negotiation between war-ravaged refugees and refugee medicine, the latter a convenient colonization of victims to suit American notions of health and welfare. Consider the defense-infused language of medicine evident in phrases such as "fighting cancer" or "battling AIDS," "fortifying the immune system" or "building immunological defenses." 31 While American military powers benefited from the battling, fortifying, and fighting exhibited by Hmong soldiers on behalf of the U.S., these Southeast Asian soldiers' eventual status as refugees, subject to Western medicine's narratives of disease and diagnosis, relegate what is an acceptable or unacceptable fight-asresistance narrative within internal colonialism, a point I will return to in the third section of the essay.

This resonates with refugee management, the socialization of refugees in order to reinscribe limitations that eventually necessitate the civilizing care of a "first nation." 32 U.S. Hmong refugee "dispersal" occurred among "53 cities in 25 different states," in which they were 
"spread like a thin layer of butter through the country so they'd disappear." 33 When Southeast Asian families pack up and move from designated refugee locales in order to be closer to relatives, often in cities boasting large Southeast Asian populations, they work against their stereotype as the model minority. Furthermore, their strategies at finding and creating critical mass in national locations prove a "masculine" gesture on a now passive nation that is unable to stop their internal migration, toppling an expected Asian American feminization, an expected obedience and passivity. ${ }^{34}$ The image of the domesticated Asian arises, again, from a history of so-called emasculated Chinese immigrant "bachelors"” who were tethered to so-called feminine forms of employment—such as busing tables, washing and pressing laundry, cooking foodwhen their application to other jobs only fueled the fire of White antagonism over scarce employment. $^{35}$ More recently, the Vietnamese "enemy" during the War acquired the appellation "gook" that highlights wild, untamed feminine representations and proved invaluable in promoting American soldiers' military mentality of assumed dominance over an inferior, effeminate Asian enemy. ${ }^{36}$ The designation of Asians as the model minority since the $1960 \mathrm{~s}-$ what I view as a continuation of the feminized, passive, obedient subject—becomes a disjunction between their "enjoyment" of model minority status and the fact that Asian American intellect has never eclipsed historical stereotypes surrounding their bodily presence as a threat. ${ }^{37}$

The Lee's noncompliance grates against such a history of expected Asian American/feminized obedience. While non-Asian patients certainly express noncompliance more often than not, the book interrogates which patient's noncompliant behavior is accepted and which berated. What occurs is a medical construction of deviance that accords itself with a contrived Asian American feminization and passivity. ${ }^{38}$ As Aihwa Ong pointed out, some Southeast Asian patients practice noncompliance as a form of resistance to expected, medical behavior, to which the Lee's noncompliance fits. Briefly, in the early years of Lia's epilepsy, the Lees exhibit a certain ambivalent faith in Western biomedicine by rushing their daughter to the 
emergency room each time she has a seizure. But Lia's primary pediatricians become increasingly frustrated at their patient's confounding responses to tried and tested epileptic medications. That the Lees resisted MCMC's medical authority to embrace a so-called lesservalued mytho-cultural authority; and that Lia's seizures remained uncontrollable through usually effective medical routes, contribute to the Lees' categorization as "difficult" and "noncompliant." The Lees struggle with all aspects of their daughter's care, hardly complacent in a crosscultural context that befuddles them. Unable to speak or read English or arabic numerals, they are overwhelmed with verbal and written hospital interaction and with the diagnostic directions of Lia's "confounding" and ever changing drug regimen. ${ }^{39}$ They do not understand measurement concepts such as "one teaspoon," and their notion of time is dictated not by a clock, but rather by the crowing of the cock. Finally, as the Lees witness hyperactivity as side effects of the drug Tegretol or the subduing effects of phenobarbital, they create a drug regimen in accordance with what they believe is best for their daughter, but a regimen antithetical to what her physicians deem best for Lia. ${ }^{40}$ The Lees' defiance marks their deviance. The more the Lees resisted via this avenue of drug (mis)compliance, the more adamantly the medical staff attempted to socialize them into the parameters of "proper" patient behavior,

Physician Neil Ernst's solution amid this economy of power and knowledge both reifies and questions his medical authority. Although the "doctors only saw her [Lia] when she was sick and never in her [loving] home environment," states Effie Bunch, a visiting public health nurse, Neil finally removes Lia from her loving home arena, accusing the Lees of child endangerment, "a form of child abuse" $(55,79)$. Lia is first lodged with two Mennonite sisters who strap her to an infant car seat in their living room during bouts of hyperactivity, a feasible drug side effect (as her parents have noted already, with chagrin, about the drug Depakene), and not the antics of a naughty child as their particularly cruel solution seems to suggest. The sisters' reaction begs the question, why should (and how can) a sick child be strapped into submission? Or even into 
health? Later, with the Korda foster family, Lia cries for days (up to 10 until sedated), and urinates and defecates on the floor, unusual behavior for this toilet trained child. Even though Lia receives the prescribed doses of medicine during her stint in foster care, she has seizures more often here than when in the custody of her biological parents who do not follow her medical regime in the painstaking details of the foster care givers $(81,87,88)$. I question, then, if Neil's unsubstantiated assessments about drug noncompliance contributed to the corporeal abuse meted out upon Lia's body through continued seizures. In Lia's case, what type of substandard care, if any, becomes the fallout from Neil's misunderstandings over the Lees' so-called defiance and disrespect? Physician Dan Murphy, whom Fadiman interviews, says that "[p]eople in the early years of their medical careers have invested an incredible amount of time and energy and pain in their training, and they have been taught that what they've learned in medical school is the only legitimate way to approach health problems" (76, emphasis mine). And he admits, in a statement so fitting to an essay critiquing power, that "They [Hmong] won't do something just because somebody more powerful says do it" (71). Why does Murphy assume that he is inherently "more powerful"- -however that might be defined — than his patients? How does one incorporate into these terms of empowerment the "incredible amount of time, energy, and pain" expended by Hmong refugees not only in their contributions to the American war effort in Vietnam, but also in their flight from Laos to the United States?

In November of 1986, Lia suffers a seizure that effectively shuts down her brain, rendering her "Comatose. Brain Damage[d]. Vegetable." She is "quadriplegic, spastic, incontinent, and incapable of purposeful movement" $(151,210)$. Much to the hospital's surprise, Lia lives far beyond the hours and days the hospital staff expects. By the book's conclusion, Lia is still alive at seven years of age - two years after her doctors expected her to die - continuing to baffle medical-rational authority. Lia's family loving accepts her as the person she still is. Once at home, Nao Kao and Fuoa care for her around the clock, first in those days where death was 
"imminent," then for years thereafter, feeding, changing, carrying, sleeping with, and loving a child in "a persistent vegetative state" (210). Fadiman's text, and I believe Fadiman herself, begs the question, "Why not?" According to MCMC staff, the Lees' loving and protective behavior, consistent throughout Lia's life, only now "miraculously [transforms them] from child abusers to model caregivers" (214), exemplifying that "deviant" others are acceptable only when their actions are deemed appropriate to Western ideals. Indeed, as long as Asian Americans remain compliant, they are easily accepted into the American fold.

That many of Lia's seizures were recorded as ideopathic $(30)^{41}$; and that other Hmong complaints like SUNDS rest in no organic cause becomes a mirror to an attendant inability to make national sense of, and therefore incorporate, the Hmong and their beliefs except as members of an ironically described "celebratory" multiculturalism, a footnote in a continuously evolving and contested American culture. If the Lees envision that "the crisis was the treatment, not epilepsy," then Fadiman's work suggests that it is both Hmong and biomedical belief structures themselves, and how we understand them, that demand change (53). Fadiman does not advocate a total investment in shamanism over medical solutions, but rather observes that Lia's MCMC health care providers should have dignified the Lees' beliefs - asked them for explanations, listened thoughtfully, acknowledged their validity in Hmong belief, even encouraged shaman use (what harm could it do?) — in light of the urgency exacerbated by existing crosscultural tensions. While biomedicine works effectively in the Western social context from which it has arisen, so, too, has shamanism proven effective in certain historical and social conditions, providing comforting explanations of terrifying behavior and offering community-based mechanisms for healing. In no uncertain terms, the Asian/American body is assigned and or denied value according to American cultural and political convenience, clearly unmasking that "foreign" others and the cultural narratives they embody continue to be accepted or rejected on a negotiated basis. $^{42}$ Lia's case therefore raises intriguing questions about how the Hmong have been marked 
indelibly by U.S. contact; and in turn, how the U.S. has been forced to accommodate them in ways whose initial frictions have been resolved by attempting to pathologize, socialize, and colonize them. Lia's treatment highlights how Asian American bodies are a reminder of how abstract political concerns play themselves out on concrete, somatic selves.

\section{Reading a Reading}

In an interview by Ron Hogan, Fadiman explains how her encounter with the Lees happened by chance, and how her motivation to pursue the family's story arose from the excitement of looking at one case via two views: “...if I could take one case and look at it from both points of view — the doctor's and the patient's — I might have something really interesting.,43 Her results conclude in an honest and publicly accepted attempt-exemplified in the numerous awards that Fadiman garnered for her work ${ }^{44}$ - to understand and record the difficulties involved on both sides, The book's complexity serves many purposes: as an introduction to Hmong culture and history; as a cautionary tale —-for the casual reader as well as the first-year medical or nursing student — of the limits of medical knowledge; as a primer on expected and accepted immigrant behavior and the consequences of expecting assimilationist practices in a nation often promoting their resistant actions.

And yet, Fadiman cannot help but write from her own Western, cultural context even as she seeks to see both sides. Her underlying investigative motivation relentlessly pursues why Lia's care was so fraught with conflict and anger on the part of Fuoa, Nao Koa, and Lia's hospital staff. In order to answer her own questions, she contextualizes Hmong history, culture, and Hmong refugee circumstances - new to Fadiman herself (she admits) — and, as she suspects, to her readers as well, thus coding her readers as non-Hmong. To a lessor degree, Fadiman also outlines the pre-refugee Merced County community and makes brief reference to the backgrounds and medical training of Lia's primary pediatricians, Neil and Peggy. Fadiman's sympathies list toward the Lees, and she is more critical of the MCMC staff, an opinion garnered when she 
quotes Arthur Kleinman (260-261). She seems to find an answer to how Lia's case should have been handled through Kleinman's "model of mediation," one dedicated to compromise, and not coercion, between patient and physician (261), one legitimizing not only the physician's version of the pathography, but also that of the patient and her culture. But her weighty emphasis on Hmong people and culture vis-à-vis a dearth of information about the equally mysterious and relatively unknown culture of medicine — at least to the lay person-resonates uncomfortably with assumptions about "others" created in "our" own naïve understandings of ourselves. In many ways, Fadiman's text assumes that her readers understand why Lia's physicians tried so hard to indoctrinate her parents into the medical model; it simultaneously assumes that readers need a "logical" explanation for the Lees" "abnormal" resistance, thus necessitating Fadiman's contextualization of the Hmong in general, the Lees in particular. The text therefore raises troubling assumptions about literary intent (to inform the "West" about the "East"/Hmong) in a book whose aim is to bridge, not contribute to, crosscultural misunderstandings. Such discursive frictions destabilize any simple categorization of authorial or textual intent and their resultant readings.

To be fair, however, Fadiman's captivating read presents what could be dry and unpalatable historical reporting as pedagogical work without dogmatism. She consults sourcesthose more reputable than a dependence on National Geographic-and interviews all of the case's participants in order to hear firsthand versions of each narrative. In fact, according to one of Spirit's reviewers, Fadiman succeeds in "intimately reveal[ing] the Hmong to the reader." 45 On the whole, Fadiman remains sensitive to her subjects, but at times, her narrative risks reestablishing the pitfalls of cultural typing she so vehemently guards against. Fadiman herself does not heed the limits of cultural knowing, however, for she privileges Westerncentric logic in many instances. Fadiman, who has exhibited an enormous measure of self-consciousness concerning MCMC's medical practices, at times becomes unself-conscious about her own 
culturally confined representations. The book, for example, is framed by what Fadiman represents as a "typical" Hmong birth and a Hmong shaman healing ceremony, both of which subtly inform (even direct) how we view the Lees: with a certain awe and fascination at their "exotic" ways. In the opening pages, a laboring Hmong woman silently delivers her child, into her own hands, in her dirt-floored home in Laos. The event is ritualistic in that all of her children have been born in such a manner, and only the newborn's cries disturb the assembled group of sleeping children (a subtle comment on the high birthrate among Lao Hmong). The view establishes a dichotomy between Hmong and "American" births. It becomes a seemingly neutral reporting of the facts that retain narrative suasion by rendering the American side—and all of its own idiosyncrasies —invisibly acceptable vis-à-vis a "third world" delivery. ${ }^{46}$ Thus, one might ask if Fadiman is re-naturalizing the always and already naturalized contours of "alien" thought and practice, as in the "third world" woman seemingly more tolerant of pain (it is the newborn who cries out and not the laboring mother). What reassurances about "us" and "them" does Spirit offer a naïve reader?

Fadiman's representations of the Hmong contextualize the Lees' beliefs, practices, fears, and reactions to make them graspable, palatable, more easily acceptable to her reading audience. According to several of Spirit's reviewers, themselves Hmong, the book "romanticizes," exaggerates, or misrepresents Hmong culture. According to Mai Na M. Lee, Fadiman falsely attributes the Lees' fighting spirit to a history of Hmong persecution, thus endowing all Hmong, in the U.S. and Laos alike, with an admirable stereotype-as-trait. ${ }^{47}$ This American designation is, in fact, a domestication of resistance or deviance. For an ethnic group to be endowed with a fighting spirit renders admirable the use of that spirit against a common enemy-the Vietcong, for example - while simultaneously denying, even vilifying its potential to overturn racist U.S.based practices as in refugee management. If, for example, the Lee's so-called fighting spirit contributes to their medical deviance, it is no long constructive nor is it admirable. The basic 
tenet of a celebratory Asian American fighting spirit has an analogue in the trajectory of Asian Americans as model minorities as long as the spirit is employed in and contained to practices deemed acceptable to the nation's political objectives of containing Asian Americans. As such, culture's and medicine's colonialist containment of the Hmong does, indeed, work toward the common purpose of constant ethnic reconstruction. Ellen Wiewell, reviewing the book for Medical Anthropology, regards Fadiman's attempts to historicize and contextualize the Hmong as "sincere" - as a legitimation of Fadiman as a source of knowledge-yet she worries over her “zealousness ... at coming up with a definitive Hmong culture. ... She uses knowledge garnered from Hmong leaders to forward her thesis about the nature of the clash between the Lees and California health care" when it "is impossible to judge the weight of the figures that Fadiman interviewed as representatives of Hmong organizations." 48

According to Fadiman, the negative, medical categorization of epilepsy runs counter to that of the Lees' simple acceptance of Lia's condition, which angered the MCMC hospital staff witnessing or hearing of the 17 devastating seizures she endures, between the ages of eight months and four-and-a-half years, some bouts continuing for up to 20 minutes (depriving her brain of oxygen and contributing to her mental retardation) (38-39). When commenting on Fadiman's observation that the Hmong place epileptics in high regard, reviewer Lee, who is Hmong herself and grew up in a Hmong community, only remembers "the stigma attached to the disease. Aside from leprosy, Hmong people fear epilepsy the most, and the fact that the Hmong attribute its causes to spirit possession makes it even more frightening to them." ${ }^{49}$ The "highly idealistic" representation that Fadiman attributes to Lia's epilepsy has a heavy hand in crafting readerly response toward the Lees.

On the one hand, Fadiman creates a valuable narrative answering many questions about Hmong culture; on the other, the text's drive to produce reasonable answers for what we may deem unusual or irrational actions points to the narrative's inability to acknowledge that some 
aspects of Hmong culture, for the Western reader, are unknowable. It is just this tension between complimenting Fadiman and chastising her that offers a reading of Spirit by which one can view how the author often succumbs to the very ethnic pitfalls she initially exposes and condemns.

Contrary to a need to understand everything that one writes about or all that one reads about concerning ethnic subjects, there exists a certain efficacy in textual lacunae-whether ideas that cannot be translated or those which the author's subject refuses to translate. And filling those gaps as an authorial, editorial, or readerly obligation often results in romanticization and stereotype, as Spirit's reviewers have outlined. Doris Sommer reveals the efficacy of making readers "worry" as they read, a tenet of many minority works. She advises her readers to "proceed with caution," the title of her book, allowing that sometimes, for example, "a trauma story wisely refuses to satisfy impertinent curiosity" (xii). "Worry should be part of the work, if we learn to read the distance written into some ethnically marked literature" (xi). ${ }^{50}$ She continues, "The lessons in listening for surprises and pausing before they are neutralized; the training to stretch our expectations of difference and to recoil from quests for mastery-these may be universal markers of literature worth discussing" (xi-xii). My point is that amid Fadiman's predominantly culturally sensitive approaches to her various "texts" lurks the urge, sometimes satisfied, to overcompensate for the unknown, whether by overlooking Western medicine itself as a mysterious entity for the layperson in order to highlight the "mysterious" Hmong; or whether privileging Western logic. It is true that Fadiman resists taking sides. Yet within Spirit two narratives are sublated: on the one hand, her sympathies often lie with the Lees and thus she critiques Western biomedicine; but in her propensity to unconsciously fall back upon her Westerncentric presuppositions, her observations stereotype her subjects in a manner reestablishing the caveats she desires to dismantle.

As a non-medical practitioner, Fadiman's, and other lay readers', familiarity with Western medicine arises from the historical and social conditions that privilege and endorse it, 
Medical, Racist, and Colonial Constructions of Power: Creating the Asian American Patient and the Cultural Citizen in Anne Fadiman's The Spirit Catches You and You Fall Down by Monica Chiu, Ph.D. Hmong Studies Journal, 2004-05, 5: 1-36.

rendering practices that fall outside biomedical models less easily admired or accepted. In fact, like the Hmong who believe in and seek out shamanism (detrimental to successful care), much of biomedical narrative (and even cure) relies on patients' acceptance of medical explanation and diagnosis. Indeed, we seek it out. Such narrative expectations themselves contribute to shaping health care workers' attitudes and practices, including "deviant" ones. That the medical profession is its own cultural laboratory, producing physicians, is witnessed in a profusion of autobiographical books that chart—or rather demystify—-the process of medical acculturation from "raw" student to polished physician. Such books become a "politics of representations" in their "reproduction of medical domains" 51 : Melvin J. Konner's Becoming a Doctor: A Journey of Initiation In Medical School; Michelle Harrison's A Woman In Residence; Kenyon J. Rainer's First Do No Harm: Reflections on Becoming a Brain Surgeon; Howard S. Becker, ed. et al., Boys in White: Student Culture in Medical School; Ellen Lerner Rothman's White Coat: Becoming a Doctor at Harvard Medical School; Perri Klass's A Not Entirely Benign Procedure: Four Years As a Medical Student; Sayantani DasGupta's Her Own Medicine: A Woman's Journey From Student to Doctor; Steve Giergerich's Body of Knowledge: One Semester of Gross Anatomy, the Gateway to Becoming a Doctor. Tellingly, the books are published by nonuniversity or crossover presses such as Ballantine, Scribner, Penguin, or Quill, suggesting that an interest in the cultural construction of medicine is hardly relegated to a strict academic audience. It bolsters the notion that a nonmedical reading public acknowledges the existence of a medical culture, one so complicated it warrants a passel of explanatory texts. David B. Morris, for example, states that "Western medicine for over a century has worked to perfect a dominant scientific discourse based on viewing disease as the product of biological and chemical mechanisms within the body-a view for which the biomedical model provides a convenient shorthand - and this traditional biomedical model remains, despite resistance, slippage, and some outright defections, entrenched as the ruling paradigm of contemporary Western medicine." 52 Therefore, this constructed medical 
arena is no less influential to the larger understanding of Lia's case than an introduction to, say, how the construction of "primitive" Hmong religious beliefs influence Hmong attitudes toward biomedicine. Such a foray insists on questions of audience. We can accept that the majority of Fadiman's readers are non-Hmong, hence justifying her trajectories into Hmong culture and history. But in that same vein, we can safely assume that many, but not all, of her readers are unaffiliated with the medical profession. Thus her elision of medicine's culture and history suggests its "universal" acceptance and understanding.

Fadiman's assumptions about what is accepted (MCMC's biomedical model) and what demands explanation (the Hmong) resonate with an economy of knowledge and power: who possesses knowledge and how is power-knowledge put to cultural use? For example, Fadiman takes great lengths in preparing for her initial meeting with the Lees, not only locating a necessary translator, but also educating herself in Hmong etiquette, hoping not to offend, threaten, or seem critical. "Meeting a Hmong is like getting into a speakeasy: everything depends on who sent you" (97). Fadiman describes no similar preparations before meeting Lia's physicians most evidently because she has acculturated the proper American etiquette of the deference that is expected of her in the clinical setting. Fadiman's physical descriptions work similarly toward rendering invisible the manner in which cultural stereotyping is bound up in our own entrenched cultural knowledge. This is attributed, in part, to our (and my) acceptance of Western anthropological narratives: explanations of an "other" cannot but be contextualized against our own, accepted, cultural norms. Fadiman describes the Lees as "good-looking, Fuoa with "glossy black hair" and Nao Kao who looks "intellectual and a little nerdy" in a pair of thick, black glasses. As well, both are "short, and although neither were fat, they looked wellrooted, as if it would take a gale force wind, or maybe even an earthquake, to knock them over" (97-98). In contrast, physical descriptions of Neil and Peggy are taken from their pre-med days: they are "tall, good-looking, athletic ... students." For the rest, their personalities and intelligence 
are emphasized as description: they were "a combination of idealism and workaholism that had simultaneously contributed to their successes"; "Neil's curriculum vitae ... [was] flush with academic and professional honors" (41). Whereas Nao Kao "looks intelligent," one might question if Neil's medical successes reify that "looking" is not "being" intelligent. What is the referent for "intelligence"-intelligent in what? - and how is the term defined? Furthermore, the Lees' determination is metaphorized through references to natural forces-gale winds and earthquakes cannot shake their resolve — and thus primitivizes them by unnaturally naturalizing a relationship between the former agrarians and their so-called connection to the earth. While Neil and Peggy possess a strong self-determination that seems equally unshakable, their physical/intellectual references remain free of a kind of coded National Geographic language. And what could be more successful, even intelligent, than escaping the murderous bent of the Pathet Lao, surviving Thai transit camps, and starting one's life over in a cultural realm that views, to their surprise, qaug dab peg (the spirit catches you) as "an electromagnetic storm" in the brain?

Furthermore, Fadiman's own failure to comment about curious MCMC staff utterances beg interpretation. An MCMC nurse, for example, witnesses Lia's decline from a headstrong but demonstrative and very active toddler to one who increasingly exhibits mental retardation, stumbles "drunkenly" on medication, or has uncontrollable seizures "when the spirit catches her." The nurse quickly describes her as a "blowfly flitting about, just totally out of control and wild and unsocialized but-well, absolutely adorable" (113). The quote provokes no textual musings from Fadiman, the text's cultural arbiter, who might have demanded, here, if "Asian" were being coded as "wild"? Is Lia completely adorable because she is Asian, a trait that demands taming? Or is Lia wild and unsocialized because she is "high" on drugs? To what should Lia be socialized-into whose society? As well, Fadiman's impressions of institutionalized children become a reference by which to read Lia's loving home care: institutionalized children, Fadiman 
observes, are "pasty-skinned carcasses with slack mouths" (216). Even though she intends to compliment the Lees on their tender, parental care of a daughter now in a vegetative state-Lia's hair is always neatly combed, shiny and black; she is "cuddled" and "rocked" and "sang to," played with by her siblings, she even "smelled delicious" (216)—her harsh words reveal disturbing biases about "clean" and "dirty" children. Thus, what meanings does Fadiman's text create about illness and about health? Or, as the Lees themselves already question, how might institutions render their patients sicker?

The process by which Fadiman and her readers are acculturated into beliefs and accepted behaviors informs one's reading of Fadiman's text. However, such seemingly invisible narratives adopt very visible parameters wherein the Lees' "mysterious" Hmongness figures as importantly in - or figures $a s$ - the "cultural collisions" of Lia's experiences. The type of so-called negative worry prompted from such a reading arises out of the necessity to mitigate the positive worry (or unexplained but necessary gaps) that Sommer finds so valuable in reading texts by and about Others.

\section{Narrative, Wound Closure, and Maintaining Respectful Gaps}

In an essay about colonizing narratives, I conclude with the impulses that narrative invites. I consider three narrative stances whose strands are both related and divergent. The tension created among such stratified theories of reading, applied to Lia's case along medical, political, authorial, and interpretive avenues, contribute to its fraught results while offering a few, final thoughts to my reading of the book's "cultural collisions."

According to Robert Leigh Davis, narrative's natural propensity to connect parts to the whole is useful in reading medicine's driving narrative force. Examining the written work of surgeon-writer Richard Selzer, Davis finds a "restorative impulse" in both surgery and Selzer's prose, "the conservative impulse to close off disruption and "make whole what is sick or injured." Likewise, a surgeon such as Selzer needs to "stabilize and control the experience of 
illness-[in relation to] the writer's need to construct 'a beginning, a middle and an end.'”53 Western medicine seeks to logically explain illnesses and subsequently prescribe a course of action (whether medication, exercise, rest, physical or psychological therapy, altered diet, surgery, radiation, etc.) to bring about expected results. Yet everyday, physicians also accept that not all ills can be cured and that while death is not the hoped-for final paragraph, it represents both a literal and figurative ending point.

A Hmong oral narrative often begins with the phrase hais cuaj txub kaum txub, or "to speak of all kinds of things." It is "a way of reminding the listeners," states Anne Fadiman, "that the world is full of things that may not seem to be connected but actually are; that no event occurs in isolation; that you can miss a lot by sticking to the point; and the storyteller is likely to be rather long-winded" (Fadiman 12-13). Yet, Sommer, referenced earlier in her advice about readers' worry, warns us to be careful of certain texts, for "[t]hey can sting readers who feel entitled to know everything as they approach a text, practically any text, with the conspiratorial intimacy of a potential partner." She suggests cautionary reading strategies in order to respectfully mark "cultural distance" when approaching works by (and about) minorities (ix).

The three reading strategies suggest mutual exclusivity. Medical narratives drive toward conclusion. Hmong narratives implore listeners to forge connections. Sommer excoriates readers to respect textual lacunae. Consider, furthermore, that Western narratives, medical or not, thrive on linearity, the beginning-middle-end of story to which Davis refers. To leave a reader in suspense is to cheat him/her of a reader's satisfaction. We prefer neatly wrapped-up stories, concluded whether for good or bad. In Spirit, Fadiman as researcher and narrator knows the story's outcome or conclusion—Lia's final, vegetative state, and the anger and chagrin expressed on both sides of the case's cultural divide. Thus the text's structure is a reflection of authorial crafting toward that end in order to captivate, inform, and question. Or, the end becomes the means for the rest of the book. But as with any re-told tale, meaning is shaped, as I have already 
discussed. Its crafting questions whether Fadiman's text is a palimpsest (and of what)? A revelation (of what)? A moral tale (concluding in what lessons)?

But I am too hasty in assigning Spirit's conclusion. The Lees' invitation of yet another shaman at book's end "concludes" in an inconclusive manner. In "believ[ing] that her [Lia's] condition was probably beyond the read of spiritual healing ... there was still this faintest flicker of a chance [in the Lees], not altogether extinguished even after years of failed [animal] sacrifices" (283). The possible reunification of body and soul through shamanism opens the text to possibility, to answers, and to endings that Fadiman, the Lees, and the MCMC staff cannot know. This is evident in Lia's defiance of her physicians' predictions: she continues to live after all of her life support systems are disconnected and despite predictions of her pending death. In ceding control to the shaman, the Lees willingly resign control to another, to the unknown, and live with their decisions. Meanwhile, MCMC continues to agonize over vexing questions: Neil wonders "in retrospect whether the course of her life might have been different if his hospital had offered her optimal medical care from the beginning" (41). I detect a certain anxiety in Neil's comment: is he worried that substandard care might invoke inquiries into MCMC's (and his) subtle discrimination? The uncertainty of what causes Lia's eventual demise creates consternation for physicians and many others who would prefer answers to uncertainty. Whereas the Lees' stance between hoping for the $d a b$ 's return and accepting Lia as she is represents a narrative motion from uncertainty to uncertainty.

Folklore or narrative "is the foundation on which the entire Hmong culture is based," states Dawn L. Remsing, especially because the Hmong had no written language until the 1950s and thus an oral tradition has buoyed the transfer of cultural, familial, and historical narratives. ${ }^{54}$ Hmong embroidery contributes to a narrative thematic of remembering: many first generation Hmong women create traditional story cloths, paj ntaub, that document agricultural life in the mountains of Laos, catalogue highland animals, or depict their flight from the Pathet Lao; 
furthermore, through narrative videos, some Hmong Americans teach their American-born children recent Lao political history via dramas that re-enact harrowing escapes across the Mekong River into Thailand. ${ }^{55}$ Likewise, the txiv neeb, or shaman, offers a story about Lia's condition and cure which rests in locating her frightened spirit and enticing it to return. The shaman, who links body to lost spirit and the living to the dead, becomes a copula of sorts between a beginning and an ending. The shaman's failure to link Lia's lost dab to her body represents a narrative lacking a conclusion.

While Southeast Asian refugees and immigrants themselves have impacted the nature of biomedical health care - that now increasingly provides necessary interpreters and will defer to certain cultural paradigms and practices-Fadiman's conclusionless text not only mimics the open-endedness of the Hmong narrative, but also suggests that much crosscultural work remains to be done.

My critique itself is problematic and reveals new gaps and new questions about how, as well as if, such gaps should be closed. I return to and appreciate Sommer's advancement of a necessary and respectful cultural distance - the inability, and the efficacy in that inability, to know (and retain power over) everything about another. Yet, according to Fadiman, if MCMC's biomedical practices must change, knowledge becomes that crux for alteration. Is it possible to have it both ways - to know as well as to resist an entitlement to knowing? Subsequently we might ask, is that which is unknowable crucial for healing? And who decides? If we adopt what Kleinman calls a model of mediation, and attend to a "local cultural system," in what ways have the Lees - and not solely MCMC — resisted compromise? Does Fadiman's critique of MCMC's biomedical model overlook ways in which the Lees (and the Hmong living within Merced County) also necessitate changes to their cultural adherence $?^{57}$ Finally, such an understanding and appreciation of cultural gaps as distances that cannot be closed re-open the quagmire over responsibility for cultural healing: who are the victims, who the perpetrators, and who is 
responsible for resolution? Answers are circumscribed by the privileging of context, as Spirit bears out. But at text's “end," Fadiman responsibly returns Lia's pathography to her and to the Lees. In the final pages, she illustrates how the Lees' hope for finding Lia's lost dab is directed toward yet another sacrifice and the invitation of another shaman. And we, the readers, are left pondering the gap between and among beliefs whose incommensurability now seems a little less daunting. 
1 Anne Fadiman, The Spirit Catches You and You Fall Down: A Hmong Child, Her American Doctors, and the Collision of Two Cultures (New York: Farrar, Straus, and Giroux, 1997).

2 The term Hmong refers to an ethnic group, predominantly from Laos, whom the Chinese, Thai and Lao have derogatorily named "Miao" or "Meo," which can mean "barbarians," or "bumpkins," "people who sound like cats," or "wild uncultivated grasses" (Fadiman 14).

${ }^{3}$ According to Hmong beliefs, humans are endowed with more than one soul, often up to three, but more are never disputed. See Keith Quincy's Hmong: History of a People (Cheney, Washington: Eastern Washington University Press, 1988, 1995), 88-89. Also see his chapter "The Spirit World" for a history and explanation of Hmong shamanism.

${ }^{4}$ From Robert. G. Lees' Orientals: Asian Americans in Popular Culture (Philadelphia: Temple University Press, 1999), 2.

${ }^{5}$ I thank X who articulated Lia's "double dehumanization as both ill and Hmong."

${ }^{6}$ Arthur Kleinman, for example, speaks of a "biomedical system [that] replaces [an] allegedly 'soft,' therefore devalued, psychosocial concern with meanings with the scientifically 'hard,' therefore overvalued, technical quest for the control of symptoms. See his The IIIness Narratives: Suffering, Healing, and the Human Condition (New York: Basic Books, 1988), 9. Yet Western medicine is hardly monolithic as explored by Marc Berg and Annemarie Mol, eds., Differences in Medicine: Unraveling Practices, Techniques, and Bodies (Durham: Duke University Press, 1998). But critics of Western medicine's overwhelming hegemonic practices have influenced my own use and criticism of the term "biomedicine." They recognize a wide variance in biomedical practice, including resistance to its strict parameters by biomedical practitioners themselves. Julia Epstein, for example, states, "The notion that fictive and clinical narratives might bear relation to one another has begun to seem less radical and more conceptually useful for an understanding of clinical thinking and the social functions of medicalization" in her Altered Conditions: Disease, Medicine, and Storytelling (New York: Routledge, 1995), 26.

${ }^{7}$ According to Jo Ann Koltyk, Hmong refugees negotiate their public images in order to avoid disapproval from the American society in a practice called "collective impression management" (14). See her New Pioneers in the Heartland: Hmong in Wisconsin (New York: Allyn and Bacon, 1995), 14.

${ }^{8}$ For historical sources other than those used in this essay, see for example Sucheng Chan's Hmong Means Free: Life in Laos and America (Philadelphia: Temple University Press, 1994); and Nancy D. Donelly's Changing Lives of Refugee Hmong Women (Seattle: University of Washington, 1994).

9 "The rate of death from SUNDS among Laotian-Hmong men has reached alarming proportions, being equivalent to the sum of the rates of the leading five causes of natural 
death among United States males." Shelley R. Adler, "Sudden Unexpected Nocturnal Death Syndrome Among Hmong Immigrants: Examining the Role of the 'Nightmare,"' Journal of American Folklore 104 (1991): 54-71 (54). Medical theories have tentatively attributed these deaths to "potassium deficiency, thiamin deficiency, sleep apnea, depression, culture shock, and survivor guilt [following the Vietnam War]," says Fadiman (Spirit, from the asterisked footnote on page 188), but have not been able to find any direct cause.

10 Those who address medicine and narrative in interdisciplinary fashion by forging connections to anthropology, literary theory, sociology, and psychiatry, are, most notably: Cheryl Mattingly and Linda C. Garro, Narrative and the Cultural Construction of IIIness and Healing (Berkeley: University of California Press, 2000); Kleinman, IIIness Narratives; Julia Epstein, Altered Conditions; Howard Brody, Stories of Sickness (New Haven: Yale University Press, 1987); Arthur Frank, The Wounded Storyteller: Body, IIIness, and Ethics (Chicago: University of Chicago Press, 1995); Anatole Broyard, Intoxicated By My IIIness (New York: Potter, 1992); Oliver Sacks, The Man Who Mistook His Wife for a Hat and Other Clinical Tales (New York: Perennial Library, 1987); as well as the journal Literature and Medicine's special volumes on "The Art of the Case History" 11.1 (1992) and that on "Narrative and Medical Knowledge" 13.1 (April 1994); and the extensive work of Byron J. Good and Mary-Jo DelVechhio Good, here, their "'Fiction' and 'Historicity' in Doctors' Stories: Social and Narrative Dimensions of Learning Medicine" in Mattingly and Garro's Narrative. Also See David B. Morris, IIIness and Culture in the Postmodern Age (Berkeley: University of California, 1998): "X rays and CT scans, it is well worth remembering, are not self-explanatory, not facts, but visual representations of the body, images that are often deeply ambiguous and that demand interpretation, creating the occasions for complex and not wholly scientific narratives" (273).

${ }^{11}$ The physician participates in a patient's pathography by legitimizing it through medical terminology and nosology, thus yoking "epistemology and storytelling," says Katherine Montgomery Hunter (21). Unfortunately, according to Hunter, such a process retells and reorders the patient's initial narrative. The physician decides which presented information is important and applicable to cure and what information is extraneous (62). Hence, two narratives have been created: the pathography (a patient's subjective account of "illness") and its translation (even alteration, according to Hunter) into a medical case-referred to as the "disease"-by its "medical narrator" (63). See Hunter's Doctors' Stories: The Narrative Structure of Medical Knowledge (Princeton: Princeton University Press, 1991), 13. Howard Brody also recognizes that the physician is trapped between "the uniqueness of the individual patient" and the necessity to reframe the illness "by means of generally applicable laws" in his Stories of Sickness (17).

12 Hunter, Doctors' Stories, 135.

${ }^{13}$ Ong, "Making the Biopolitical Subject," 105, 102.

${ }^{14}$ Ibid., 91.

${ }^{15}$ Epstein, Altered Conditions, 29. 
${ }^{16}$ See Alan M. Kraut, Silent Travelers: Germs, Genes, and the "Immigrant Menace" (New York: Basic Books, 1994); John Kuo Wei Tchen, "Believing Is Seeing: Transforming Orientalism and the Occidental Gaze," in Asia/America: Identities in Contemporary Asian American Art, eds. Pacita Abad, et al. (New York: New York University Press, 1994).

17 "[R]acial stereotypes have been linked with images of pathology, especially psychopathology," from the mid nineteenth century, says Sander L. Gilman in Difference and Pathology: Stereotypes of Sexuality, Race, and Madness (Ithaca: Cornell University Press, 1985), 129.

18 Nayan Shah's Contagious Divides: Epidemics and Race in San Francisco's Chinatown (Berkeley: University of California Press, 2001) is an apt example of a recent, scholarly revisitation of the Yellow Peril in order to excavate how Chinese American activists, up to the mid-twentieth century, rallied against their communities' constricting pathological designations and for their full, civic inclusion within American society.

${ }^{19}$ For Gina Marchetti, the medical scare coupling Chinese immigrants with the bubonic plague resulted in "the notion that all nonwhite people are by nature physically and intellectually inferior, morally suspect, heathen, licentious, disease-ridden, feral, violent, uncivilized, infantile, and in need of the guidance of white, Anglo-Saxon Protestants." See her Romance and the "Yellow Peril": Race, Sex, and Discursive Strategies in Hollywood Fiction (Berkeley: University of California Press, 1993), 2-3. Therefore, what we now call Yellow Peril narratives-depicting "the sinister and evil character of the quarter [Chinatown] and most of its inhabitants"-are described as "Anglo-American literature [that] does not tell us about Asians ... but tells us about Anglos' opinions of themselves, in relation to their opinions of Asians, according to Elaine $\mathrm{H}$. Kim in Asian American Literature: An Introduction to the Writings and Their Social Context (Philadelphia: Temple University Press, 1982), 20.

20 National Geographic "is continually drawn to people in brightly colored, 'different' dress, engaged in initially strange-seeming rituals or inexplicable behavior," state Catherine A. Lutz and Jane L. Collins in their thorough study of the magazine. "This view ... [is] a world of happy, classless people outside of history but evolving into it, edged with exoticism and sexuality, but knowable to some degree as individuals." How, then, do the authors ask, do such images "change or reinforce" or even influence readers' practices? See their Reading National Geographic (Chicago: University of Chicago Press, 1993), 89, 116, 117.

${ }^{21}$ See Trinh's "The Language of Nativism: Anthropology as a Scientific Conversation of Man With Man" in her Woman, Native, Other (Bloomington: Indiana University Press, 1989): 47-76.

22 Renny Christopher deems this an "ongoing meta-war, which attempts to erase the Vietnamese from their own reality and make them part of American reality." The U.S. "may have lost the shooting war," she writes, but rectifies such a blow by winning a homeland meta-war that "abstracts 'Vietnam' the war from 'Viet Nam' the country." She exemplifies how the correct spelling of the country-Viet Nam, which includes a space between the two syllables-evolved into "Vietnam" in American newspapers and finally 
within the American imagination. Not only did the U.S. misspell the nation, but any mention of "Vietnam" tends to conjure up the "conflict," as the war is euphemistically deemed, and not the country or its people. See her work The Viet Nam War, The American War: Images and Representations in Euro-American and Vietnamese Exile Narratives (Amherst: University of Massachusetts Press, 1995), 4, 7.

23 Jane Hamilton-Merritt, Tragic Mountains: The Hmong, the Americans, and the Secret Wars for Laos, 1942-1992 (Bloomington: Indiana University Press, 1993), 55, 87.

${ }^{24}$ Fadiman says of this verbal agreement between an American CIA agent, known only as "Colonel Billy, and Vang Pao, the most well-known Hmong military leader, "Every Hmong has a different version of what is commonly called the "Promise," wondering what went wrong and why they are chastised in the country for which they offered their own lives. See Fadiman's "Heroes' Welcome," Civilization: The Magazine of the Library of Congress 4.4 (August-September, 1997): 53-61 (59).

${ }^{25}$ Americans, for example, often vociferously complain that Southeast Asian refugees are community tax burdens while the protestors remain grossly ignorant of their participation during the Vietnam War, during which the Hmong lost one-third of its Laotian-based population "including half of all the males over fifteen," states Lillian Faderman in I Begin My Life All Over: The Hmong and the American Immigrant Experience (Boston: Beacon, 1998), 7. President Johnson's comment that "virtually no American casualties" occurred in Laos during the war demonstrates the value attributed to some human lives and tragically denied to others. (Fadiman, "Heroes' Welcome," 55).

${ }^{26}$ Hamilton-Merritt, 519, emphasis in text.

${ }^{27}$ The Lees twice tried escaping to Thailand, the first attempt ending in capture by Vietnamese soldiers and the death of one child; they spent three years guarded by armed soldiers - witnessing the starvation of another child — until their second escape attempt with a group of about 400 other Hmong. Vietnamese soldiers attempted to burn them out of the jungle while some children (not those of the Lees) were shot over and over until "their heads were squashed." The dangerous journey, on foot, to the Thai border lasted 26 days, after which they spent two years in a Thai transit camp, losing one daughter there (Fadiman, Spirit, 155-157).

${ }^{28}$ If at one time Hmong soldiers were an invisible body, they become highly and visibly corporeal, as refugees, in all their rumored idiosyncrasies, often those that conflict with accepted Western beliefs (eating skunks and cat food, rinsing rice in the toilet, washing clothes in public pools, picking their ears and noses in public). See Spirit 186-188.

${ }^{29}$ MCMC staff, for example, are stupefied and angered over Fuoa's fifteenth pregnancy. However, they remained ignorant of a former Hmong agrarian existence that necessitated large families; as well, frequent deaths, including the massacre of Hmong during the Vietnam War, now drives their strong desires to reproduce; and the practice of marrying at a very young age facilitates a long period of active fertility, which is coupled with Hmong intense love of children, "the most treasured possession[s] a person can have" (Fadiman 21-22). Fadiman quotes ethnographer Hugo Adolf Bernatzik 
who lived with the Hmong in Thailand during the 1930s. See Spirit for Hmong "reasons for prizing fecundity" (specifically page 72).

${ }^{30}$ Kleinman, IIIness Narratives, 25.

31 See Susan Sontag's IIIness as Metaphor and AIDS and Its Metaphors (New York: Anchor, 1978, 1989), 57. Also see Scott L. Montgomery's Of Codes and Combat: Images of Disease in Biomedical Discourse," Science as Culture 12 (1991): 55-73.

32 Jeremy Hein, From Vietnam. Laos, and Cambodia: A Refugee Experience in the United States (New York: Twayne, 1995), 24.

${ }^{33}$ Fadiman, "Heroes' Welcome," 56.

${ }^{34}$ For an astute presentation of how the "feminized" East dupes the so-called masculine West, reversing the stereotyped roles, see David Henry Hwang's M. Butterfly (New York: Penguin, 1988, 1989).

${ }^{35}$ Given the Chinese men's social exclusion as an unclean peril, it is ironic that Chinese immigrant men found their employment limited to food service and cleaning underclothes, arenas that traditionally demand employees' overt cleanliness and good health in their covert connection to consumers' intimate personal hygiene (gastronomy and underwear).

${ }^{36}$ See Jacqueline E. Lawson, "'She's a Pretty Woman . . . for a Gook.' The Misogyny of the Vietnam War" in Fourteen Landing Zones: Approaches to Vietnam War Literature. Ed. Philip K. Jason (lowa City: University of lowa Press, 1991), 23. Lawson illustrates how the language of combat itself is riddled with sexual innuendoes and domination in words such as pacification, engagement, escalation, de-escalation, withdrawal, humping the boonies, and cherry (a soldier without battle experience) (24).

${ }^{37}$ This is evident in recent controversies over Asian Americans' abundant presence on campuses in California and Texas; accusations over campaign financing during Clinton's run for presidency; and the spying allegations against Wen Ho Lee, to name a few.

${ }^{38}$ I thank $X$ for pointing out connections between medicine's definition of noncompliance and culture's construction of the feminized Asian American.

${ }^{39}$ Fadiman writes, "Over time, her drug regimen became so complicated and underwent so many revisions that keeping track of it would have been a monumental task even for a family that could read English. For the Lees, it proved to be utterly confounding" (45).

40 A public health nurse notes, "Father had become more and more reluctant to give medications at all because he feels that the medicines are causing seizure and also the fever" (50). During one of Fadiman's interviews with Nao Kao, he angrily states, "I am very disappointed at the hospital. I am mad. Is this a hospital that fixes people or makes them die?" (177). 
${ }^{41}$ More specifically, while the attribution of Lia's affliction to a spirit is unscientifically based, Fadiman reports, it is no more or less enlightening than those gaps in Western medicine's knowledge which reference seven epileptic cases out of ten that are ideopathic or untraceable to any known cause (Fadiman 28-29).

42 See Christopher's The Viet Nam War (cited earlier) in which she discusses, specifically, Euro-American images of Asians in popular culture as a "result of U.S. wars in Asia," and how these images contributed to "the lens through which most EuroAmerican works representing the war in Viet Nam view Vietnamese" (21). She speaks of how "many U.S. narratives complain of the supposed 'impossibility' of telling the enemy from the civilians" (6), a concept whose stateside translation is the outbreak of American anger and frustration toward Southeast Asian refugees whose help was necessary and valuable "over there" but whose present cry for help is now perceived as a governmental drain.

${ }^{43}$ Ron Hogan, "Beatrice Interview," http://www.beatrice.com/interviews/fadiman/.

${ }^{44}$ Winner of the National Book Critics Circle Award for General Nonfiction; Los Angeles Times Book Prize for Current Interest; A Salon Book Award Winner; Boston Book Review 1997; Ann Rea Jewell Non-Fiction Prize; A New York Times Notable Book; A Best Book of the Year (People, Newsday, Glamour, and the Detroit Free Press); Finalist PEN / Martha Albrand Award for First Nonfiction. From http://www.spiritcatchesyou.com/pressroom.htm.

${ }^{45}$ Mai Na M. Lee, http://www.hmongnet.org/publications/spirit review.html.

${ }^{46}$ In Mai Lee's review, she states that it is highly "improbable" and "unbelievable" that any Hmong woman birthed twelve children by herself, as village female elders would have been in assistance and that such a birthing tale was most likely "to metaphorically convey the general hardship of Hmong women and should not be taken seriously."

${ }^{47}$ Ellen Wiewel states," I found her application of the cultural description [that the Hmong are 'strong-willed'] to be burdensome, because she occasionally used it to stereotype Hmong behavior. ... Fadiman derived the fight or flight reaction of individual Hmong in America, from the entire group's response when their Laotian highland territory was challenged." Wiewel's "Review and Assessment of The Spirit Catches You and You Fall Down," Medical Anthropology (Fall 1999): http://www.imsa.edu/ elbel/spirit.html.com.

${ }^{48}$ Wiewel says that Fadiman "treats Hmong culture idealistically and stereotypically at times."

${ }^{49}$ Reviewer Mai Lee takes issues with the following paragraph from Spirit: "The history of the Hmong yields several lessons that anyone who deals with them might do well to remember. Among the most obvious of these are that the Hmong do not like to take orders; that they do not like to lose; that they would rather flee, fight, or die than surrender; that they are not intimidated by being outnumbered; that they are rarely persuaded that the customs of other culture, even those more powerful than their own, are superior, and that they are capable of getting very angry." Lee deems it Fadiman's romanticization that unfortunately guides many of her Hmong representations. 
50 Doris Sommer, Proceed With Caution, When Engaged by Minority Writing in the Americas (Cambridge: Harvard University Press, 1999).

51 Donald Pollack, "Physician Autobiography: Narrative and the Social History of Medicine," in Mattingly and Garro's Narrative $(110,109)$. Pollack addresses the "genre" of the "training tale" and accounts of "gender in medicine," most of which begin with the "end" of medical school or residency as a point by which graduated medical students and board-certified physicians reflect on who they have become and how.

52 Morris, IIIness and Culture, 72. He conclusively states, "Postmodern illness is fundamentally biocultural-always biological and always cultural-situated at the crossroads of biology and culture" (71, emphasis in text). And Miriam E. Warner and Marilyn Mochel state that "Western biomedicine is a culture" (quoted in "The Hmong and Health Care in Merced, California," Hmong Studies Journal 2.2 [Spring 1998]: http://www.como.stpaul.k12.mn.us/Vue-Benson/HSJ-v2n2.html.)

53 Robert Leigh Davis, "The Art of Suture: Richard Selzer and Medical Narrative," Literature and Medicine 12.2 (Fall 1993): 178-193 (179, 181).

${ }^{54}$ Dawn L. Remsing, Hmong Folklore: The Art of Storytelling, (M.A. Thesis, University of Wisconsin-Eau Claire, August 1996), 1.

55 See Sally Peterson's "Translating Experience and the Reading of a Story Cloth," Journal of American Folklore 101 (1988): 6-22; and Jo Ann Koltyk's "Telling Narratives Through Home Videos: Hmong Refugees and Self-Documentation of Life in the Old and New Country," Journal of American Folklore 106.422 (1933): 435-449.

${ }^{56}$ Kleinman, IIIness Narratives, 27.

57 This is Spirit reviewer Weiwel's contention as well: "Fadiman did not offer any suggestions for the Hmong to show more interest in working with the doctors. ... She briefly mentioned the Hmong National Development organization's efforts (page 198), but she vastly portrayed Lia's family's situation as a travesty on the part of the biomedical system. We know we want to change the biomedical establishment, because it failed Lia on cultural grounds. But for biomedicine to successfully meet the needs of specific groups such as the Hmong, it needs input from the Hmong themselves" (no page numbers in the online article). 


\section{$\underline{\text { Author Information }}$}

Monica Chiu is Associate Professor of English at the University of New Hampshire, where she teaches courses in Asian American literature, Asian American film, American literature, and literature and the body. She is the author of Filthy Fictions: Asian American Literature by Women as well as essays that appear in LIT: Literature, Interpretation, Theory; Mosaic; MELUS; and The Journal of American Literature.

Dr. Monica Chiu

Associate Professor of English

English Department

University of New Hampshire

Durham, NH 03824

Monica.chiu@unh.edu

603.862.0732 